\title{
O PARTIDO POLÍTICO NAS TEORIAS DO BEM-ESTAR SOCIAL: DA AGREGAÇÃO DE INTERESSES À AÇÃO GOVERNAMENTAL
}

\author{
Augusto Neftali Corte de Oliveira ${ }^{1}$
}

Resumo: Em democracias liberais que funcionam, os partidos são organizações capazes de conectar os interesses dos cidadãos (processo da cidadania) e as ações do governo (políticas públicas). Este processo de accountability vertical é atravessado por inúmeros fatores, de maneira que as interpretações sobre sua realização são bastante diversificadas. O objetivo central da presente pesquisa é mapear as diferentes abordagens da relação entre partidos e políticas sociais e revelar como elas resolvem no campo teórico e metodológico a integração dos processos de agregação de interesses e ação governamental. As abordagens analisadas são expostas em seis linhas: lógica do industrialismo, lógica do capitalismo, modelo pluralista, modelo social-democrata, novo institucionalismo histórico e modelo do veto-player.

Palavras-chave: partidos políticos, políticas sociais, bem-estar social.

Resumen: En las democracias liberales que funcionan, los partidos son organizaciones capaces de conectar los intereses de los ciudadanos (proceso de ciudadanía) y las acciones de gobierno (políticas públicas). Este proceso de accountability vertical está atravesado por numerosos factores, por lo que las interpretaciones de su realización son muy diversificados. El objetivo principal de esta investigación es mapear los diferentes enfoques de la relación entre los partidos y las políticas sociales y revelar cómo resuelven la integración teórica y metodológica de los procesos de agregación de intereses y acción gubernamental. Los enfoques analizados se muestran en seis líneas: la lógica del industrialismo, la lógica del capitalismo, el modelo pluralista, modelo socialdemócrata, el nuevo institucionalismo histórico e el modelo del veto-player.

Palabras-clave: partidos políticos, las políticas sociales, el bienestar social.

Abstract: In functioning liberal democracies, parties are organizations able to connect the interests of citizens (citizenship process) and the actions of government (public policy). This process of vertical accountability is crossed by numerous factors, so their interpretations are diverse. The main objective of this research is to map the approaches to the relationship between parties and social policies and reveal how they solve theoretical and methodological the integration of the processes of aggregation of interests and government action. The approaches are displayed in six lines: logic of industrialism, logic of capitalism, pluralist model, social democratic model, new institutionalism historic and veto-player model.

Key-words: political parties, social policies, social welfare.

\footnotetext{
${ }^{1}$ Mestre e doutorando em Ciência Política na Universidade Federal do Rio Grande do Sul. Esta pesquisa foi desenvolvida como parte da dissertação de mestrado do autor, orientada pela Profa. Dra. Mercedes Maria Loguercio Cánepa, e versão anterior foi apresentada no IV Seminário Nacional de Ciência Política da UFRGS. E-mail de contato: ancolive@gmail.com.
} 
A literatura costuma destacar que os partidos políticos são atores capazes de agregar preferências, apresentá-las no momento eleitoral e, quando vitoriosos, influenciar a formação de políticas públicas de maneira coerente com estas preferências. Este processo de representação ou accountability vertical não apenas está ligado à formação e transformação dos regimes de bem-estar social, como é essencial para a democracia de massas. O objetivo central da presente pesquisa é mapear as diferentes abordagens da relação entre partidos e políticas sociais e revelar as contribuições teóricas e metodológicas que elas oferecem para o estudo da accountability vertical neste campo.

Especificamente, busca-se destacar contribuições em dois sentidos: (a) na definição de parâmetros para compatibilização teórica entre os processos de agregação de interesses e de ação governamental e (b) na definição de canais e interveniências do processo de accountability vertical. $\mathrm{O}$ artigo pesquisa as abordagens expostas em seis linhas de interpretação: lógica do industrialismo, lógica do capitalismo, modelo pluralista, modelo social-democrata, novo institucionalismo histórico e modelo do veto-player. Introdutoriamente, são apresentadas algumas definições a respeito de partidos políticos e políticas sociais, que são úteis para compreensão de sua relação.

A literatura na área da ciência política construiu muitas definições para a expressão partido político. King (1969) e Schonfeld (1983) colecionam diversas, de maneira que os partidos políticos podem ser considerados: opinião organizada (Disraeli); grupos autônomos que realizam nomeações e participam de eleições na esperança de controlar o pessoal e as políticas do governo (Renney e Kendall); uma associação que ativa e mobiliza pessoas, representa interesses, provê compromissos sobre determinados pontos de vista e confere suporte para líderes (Macridis); associações formadas por livre recrutamento de seus membros, cujo fim de sua atividade é assegurar poder para seus líderes sob uma organização, visando obter vantagens ideais ou materiais para seus membros ativos (Weber); uma organização voltada para conquistar o poder, sendo esse poder o controle do governo (Schnattschneider); qualquer grupo, mesmo pouco organizado, que busca eleger cargos de governo sob determinado rótulo (Epstein).

Marshall (1998, p. 619) destaca que ambos os termos que formam o conceito "política social” são complexos: o primeiro (política) enfatiza um conjunto mais ou menos articulado de idéias, indicando objetivos e direções, a serem adotadas por determinado órgão decisório; já o segundo (social) refere-se às necessidades de determinada população (interpretadas como necessidades de bem-estar), podendo incluir seguros sociais (previdência e assistência), saúde, habitação, educação e segurança. $\mathrm{O}$ autor reforça, assim, a definição de política social já traçada por Marshall 
(1967, p. 7): "política dos Governos relacionada à ação que exerça um impacto direto sobre o bem-estar dos cidadãos, ao proporcionar-lhes serviços ou rendas”. Marshall (1998, p. 619) destaca, contudo, o problema em que consiste a diferenciação entre política social e econômica, tendo em vista que os assuntos tratados como de política econômica - como a tributação e a inflação - possuem tremendo impacto sobre o bemestar social.

\section{INDUSTRIALISMO E POLÍTICA SOCIAL}

As pesquisas guiadas pela lógica do industrialismo compreendem os processos associados ao desenvolvimento econômico, à produção industrial, à adoção de novas tecnologias e das relações sociais correspondentes como principais determinantes das condições sociais e políticas. Conforme Kerr e outros (1963, p. 46) "a industrialização é o processo que se desenrola na transição entre a sociedade tradicional e o industrialismo" e compreende "diferentes estágios de industrialização, através do longo período de transição para a sociedade completamente industrializada”.

Nessa interpretação, o governo responde às demandas das empresas sobre as condições estruturais e tecnológicas da produção e de elementos indiretos da industrialização, como a urbanização, o aumento das relações entre países, da necessidade de educação especializada e regulamentação das relações e procedimentos do trabalho. Assim, "o papel do governo em países onde a industrialização se inicia, independentemente de sua forma política, deve, conseqüentemente, aumentar" (ibidem, p. 55). Destaca-se a idéia da industrialização como elemento de explicação universal, que elucida etapas de desenvolvimento e determina as políticas do governo independentemente da atuação dos partidos políticos. Em que pesem as críticas a essas proposições, as transformações posteriores (pós-industrialismo) recolocaram a relevância dos fatores econômicos nas explicações sobre o mercado de trabalho e as políticas sociais (Esping-Andersen, 1998, p. 191).

\section{CAPITALISMO E POLÍTICA SOCIAL}

O argumento fundador das interpretações marxistas sobre a política social recorre ao papel do Estado na formação da classe operária e na manutenção das condições do processo de produção capitalista. Marx destaca que a formação inicial do proletariado passou por vencer a resistência dos trabalhadores na submissão às regras do trabalho assalariado (Marx, 1981, p. 55; 1985, p. 219). Com a consolidação e normalização destas formas de relação, passaram a surgir as primeiras iniciativas 
estatais de restrição à exploração do trabalho, pela demanda da classe operária por limitações ao mercado de trabalho: "uma lei estatal, uma barreira social intransponível, que os impeça a si mesmos de venderem a si e à sua descendência" (Marx, 1985, p. 236).

Nesta tradição, Lenhardt e Offe (1984, p. 24) definem as políticas sociais contemporâneas como "o conjunto daquelas relações e estratégias politicamente organizadas, que produzem continuamente essa transformação do proprietário da força de trabalho em trabalhador assalariado”. Os principais objetivos das políticas sociais, para os autores, são: garantir a proletarização dos trabalhadores (sua inserção normalizada no mercado de trabalho); manter níveis adequados de reprodução da força de trabalho e qualificação profissional; e permitir que a "figura do 'trabalhador médio', depurada de todas as contingências, se transforme na base de cálculo para gestão racional da empresa" (ibidem, p. 30).

Dessa maneira, a política social responde funcionalmente a três problemas estruturais decorrentes das oscilações da economia capitalista. O primeiro é a integração da força de trabalho no mercado de trabalho, motivando os trabalhadores e quebrando suas resistência ao trabalho assalariado (preparação repressiva). O segundo é a administração e coletivização dos riscos à saúde do trabalhador; e ainda o oferecimento e controle de condições de sobrevivência fora do mercado (previdência social), impedindo conflitos redistributivos abertos e agudos. Por fim, o problema do controle quantitativo do processo de proletarização, da oferta de força de trabalho, resolvido pelo gerenciamento da entrada dos trabalhadores no mercado de trabalho e das possibilidades de seu afastamento temporário ou definitivo.

A partir disso os autores afastam como fator determinante da evolução das políticas sociais a exigência da classe trabalhadora sobre o Estado ou as exigências funcionais da produção capitalista, pois as agências estatais não possuem a capacidade de mensurar estas necessidades independentemente dos atores sociais. Os autores propõem, assim, a seguinte teoria para determinação das políticas sociais:

as organizações da classe operária, ao se dirigirem ao Estado com exigências de segurança sócio-políticas, impondo-as com os meios políticos que lhes são próprios, não alcançam outra coisa senão forçar o capital a adotar medidas que correspondem ao interesse do próprio capital, e que se tornariam necessárias, a longo prazo, para assegurar uma modernização ampla das relações de exploração (Lenhardt e Offe, 1984, p. 35)

Nesse processo - que pode ser resumido na idéia de dependência estrutural do Estado ao capital - operam mecanismos de ajustes entre trabalho e capital que, nas democracias liberais, são intermediados pelo sistema competitivo de partidos políticos 
(Offe, 1993, p. 59). No entanto, Offe (1986) propõe que o desempenho deste papel depende muito das condições de identidade e semelhança geradas no próprio processo produtivo. Situações de aumento da desigualdade social ou desemprego podem resultar em "uma profunda falta de fé nas políticas sociais como 'bens públicos' e que tende a destrinchar tais políticas em termos de ganhos e perdas" (ibidem, p. 307-308).

\section{MODERNIZAÇÃO E POLÍTICA SOCIAL}

As análises que adotam argumentos centrados na atuação de grupos e setores sociais (society-centered) são bastante diversificadas, englobando grande parte da produção sobre organização política e políticas públicas na área da ciência política. Entre análises clássicas neste campo, destacam-se as focadas nas funções dos sistemas políticos (Almond e Coleman, 1969; Almond e Powell, 1972) e no processo de modernização social (Huntington, 1975). Estes trabalhos possuem expressa preocupação em expandir as explicações para fora dos países mais analisados da Europa ocidental e América do Norte e envolvem a comparação entre democracias e regimes autoritários.

Os trabalhos lidam com o conceito de sistema político, que consiste no "sistema legítimo que mantém ou modifica a ordem numa sociedade" (Almond e Coleman, 1969, p. 17) e "compreende consenso, comunidade, legitimidade, organização, eficiência, estabilidade” (Huntington, 1975, p. 13). Para os autores, as relações dadas nessas esferas são o fator chave das diferenças entre as diversas fases e estágios em que se encontram as nações, e não simplesmente a modernização econômica - como faz crer a lógica do industrialismo. Huntington (1975, p. 45 e seguintes), nesse sentido, aponta a percepção de um hiato entre os processos de modernização socioeconômica (com o crescimento da produção, industrialização, especialização profissional e maior complexidade social) e de modernização política das comunidades tradicionais, com a racionalização da autoridade, diferenciação estrutural e participação popular.

Esse hiato se manifesta na medida em que o processo de modernização socioeconômico solapa as bases da autoridade tradicional e aumenta o conflito entre os grupos sociais sem, necessariamente, dar lugar a relações políticas modernas. Ainda conforme Huntington (ibidem, p. 104), a estabilidade política na modernização pode ser obtida caso as instituições tradicionais sejam fortes o suficiente para manter sua legitimidade e oferecer respostas adequadas de bem-estar; onde isso não ocorre, os partidos ganham espaço para controlar a participação e os interesses sociais na 
reorganização das estruturas governativas fundadas sobre legitimidade ideológica, nacionalista, carismática.

O papel dos partidos políticos neste sistema corresponde ao que Almond e Coleman (1969, p. 45) entendem por agregação de interesses. Ou seja, a articulação por grupos sociais de interesses, exigências e demandas, os combinando e acomodando em diretrizes políticas que influenciam o processo de tomada de decisão. Os partidos políticos são as organizações especializadas na agregação de interesses nas sociedades modernas. Entretanto, Almond e Powell (1972, p. 140) observam que outras organizações também realizam esta função dos sistemas políticos, sendo que os partidos perdem a capacidade de agregação na medida em que adotam programas menos consistentes.

Tilly (1991) oferece diversas críticas à teoria da modernização, desdobráveis para a lógica do industrialismo e do capitalismo, principalmente por considerar a especialização e diferenciação processos progressivos e coerentes de avanço social com validade universal, desdobráveis em etapas a serem igualmente vencidas por todas as sociedades. Dentre outros fatores, a agregação de diversas variáveis e unidades sociais sob a capa de categorias abordadas nacionalmente levaria à presunção de homogeneidade em lugar de enfrentar a diversidade das construções históricas. No contexto da crítica às interpretações funcionalistas, a fragilidade dos argumentos destas análises é atribuída ao determinismo de única relação explicativa, considerada a chave para compreensão de fenômenos na realidade complexos e diversificados.

\section{PARTIDOS POLÍTICOS E POLÍTICA SOCIAL}

Os autores do trabalho organizado por Castles (1982) procuram estabelecer a correspondência entre a atuação dos partidos políticos (seja a simples presença organizada, o controle de cadeiras congressuais ou de cadeiras nos gabinetes de governos), considerando suas orientações ideológicas gerais, e as tendências do gasto político observado nos diferentes casos. Enquanto procedimentos estatísticos são utilizados para mensurar e isolar o impacto dos partidos na formação das tendências, é com a comparação entre os conjuntos de países que surgem os principais resultados das pesquisas. A principal tese mobilizada pela pesquisa é a de que "diferentes idéias políticas, expressadas por meio dos partidos, facções e grupos, interagem com as estruturas sociais e econômicas para produzir a diversidade de políticas públicas que caracterizam os estados modernos" (Castles, 1982, p. 1).

Confirmando as expectativas, Castles conclui que enquanto a direita gasta menos, os social-democratas são mais generosos. Embora no início dos anos 1960 
sejam perceptíveis apenas variações nos gastos de saúde e educação, já no início da década seguinte pode se perceber o impacto dos partidos de direita em todas as políticas, com a exceção parcial das políticas de garantia de renda (ibidem, p. 71). O autor informa que a variação nos gastos observada pode ser explicada pelo nível do gasto público geral e pela composição do governo, além da influência do passado - a situação dos gastos públicos nos anos de 1960 explicam aproximadamente a metade da variação percebida em 1970 (ibidem, p. 72). Assim, para Castles as preferências ideológicas podem afetar a forma pela qual as necessidades ou demandas de cada cidadão são transladadas em política pública.

Em outro campo de análise sobre o tema, a pesquisa de Klingemann, Hofferbert e Budge (1994), que engloba 1.200 eleições em 25 países, observa um conjunto de partidos conforme suas manifestações nos programas de governo em categorias divididas em sete grupos: relações exteriores, liberdade e democracia, governança, economia, bem-estar e qualidade de vida, socialização e grupos sociais. $\mathrm{O}$ procedimento da pesquisa é contar as frases dos programas de governo que ativam cada uma das categorias. Testes estatísticos são realizados no estudo de casa caso, para relacionar a presença das ênfases nos programas de governo com a variação do gasto público. Os autores testam três modelos: o modelo mandato, que testa o impacto das políticas programáticas dos partidos vencedores (que dominam o governo) sobre a ação governamental; o modelo ideologia, que testa a orientação histórica do partido vencedor sobre a ação governamental; e o modelo da agenda, que testa o impacto não do partido vencedor, mas dos partidos relevantes em cada sistema.

Os autores concluem que o tipo de governo (Westminster, presidencial ou de coalizão) não possui impacto relevante no nível de accountability programática no conjunto dos partidos estudados. Entretanto, três países enquadram-se no modelo de agenda (Suécia, Grã-Bretanha e França), enquanto Canadá, Bélgica, Alemanha, Holanda, Estados Unidos, Áustria e Austrália se enquadram no modelo mandato ou ideologia. Neste último caso, os partidos observam no governo tanto as disposições de seus programas eleitorais quanto a história as preferências históricas dos partidos (ibidem, p. 264). Os autores afirmam, com os resultados da pesquisa, que os partidos se mostram capazes de conectar os processos de cidadania e governamental: organizam as demandas dos cidadãos e transformam as demandas em temas políticos. Desta forma, partidos políticos agregam demandas em pacotes relativamente coerentes de políticas um processo que confere aos eleitores opção nas eleições (Ibidem, p. 270).

Os estudos de Castles e Klingemann, Hofferbert e Budge destacam como observar algumas diferenças em relação às políticas sociais que os partidos políticos representam quando estão no governo. Revelam como os partidos preferem atacar os 
desafios sociais e gastar os recursos públicos, bem como as condições em que estão aptos a exercer um impacto mais relevante. Como a pesquisa empírica dos dois estudos estringiu-se a alguns países desenvolvidos, seus resultados não podem ser simplesmente transferidos para outra realidade. Contudo, oferecem importantes contribuições para a análise do comportamento dos partidos com relação às políticas públicas, principalmente quando estão no governo ou em outras posições de poder, considerando inclusive a capacidade das forças políticas em gerar tendências diferentes em cada realidade nacional.

Embora os autores percebam que os partidos atuam cristalizando tendências nas atividades estatais, a interpretação não permite inferir sobre como os mecanismos sociais entre partidos e o Estado atuam nessas tendências. Se essas pesquisas lançaram muitas luzes sobre as circunstâncias em que os partidos se tornam relevantes, não esclarecem com a mesma força de que maneira esse impacto se desenvolve. Consoante com esse argumento, Weir e Skocpol (1999, p. 112) salientam que a capacidade dos partidos de utilizar o governo para implementar políticas de bem-estar explica as variações a partir de interpretações excessivamente teleológicas no que diz respeito aos objetivos presumidos ou observados e os resultados em termos de políticas públicas.

As análises destacadas mostram a mobilização dos partidos a partir de determinado grupo social estabelecido. Outras interpretações da relação entre partidos e políticas sociais também possuem lugar na literatura. Mulé (2001, p. 196) mostra como as políticas sociais são impactadas pela formação de facções partidárias em busca de novos apoiadores que legitimem suas pretensões políticas. No percurso da interação entre partidos no sistema partidário, bem como das relações intrapartidárias, oportunidades de rupturas que ofereçam vantagens estratégicas podem explicar mudanças partidárias, bem como alterações nas ênfases e práticas dos partidos em relação às políticas sociais.

\section{ESTADO E POLÍTICA SOCIAL}

$\mathrm{Na}$ abordagem sobre o impacto dos partidos políticos nas políticas sociais o papel do Estado permanece em segundo plano, tanto como fator de explicação quanto em relação à metodologia. As pesquisas compiladas por Evans, Rueschemeyer e Skocpol (1999) adotam comparações de tipo case-oriented, com interpretações históricas dirigidas por análises teóricas e focadas em casos específicos (número pequeno). Uma perspectiva que considera as diferentes estruturações do poder estatal, conforme os autores, pode abordar a atuação do Estado de duas formas: (a) como uma coletividade de agentes e organizações que pode possuir objetivos mais ou menos 
articulados e busca realizá-los conforme os recursos que possui em suas relações recíprocas e em face da sociedade (Skocpol, 1999, p. 9-10, p. 28); ou (b) sob o ponto de vista macroscópico, segundo o qual a configuração do Estado encoraja alguns tipos de formação de grupos e ações políticas coletivas e tornam possível a extensão de certos argumentos políticos em detrimentos de outros (ibidem, p. 21).

Skocpol (1999, p. 15) argumenta que o Estado não pode atuar de maneira desinteressada, pois toda a decisão que toma beneficia certos interesses sociais em prejuízo de outros. Dessa forma, a racionalidade de sua atuação depende de sua capacidade de avaliar soluções independentemente das pressões sociais e de coordenar decisões entre suas agências, impedindo que atuem contraditoriamente entre si e em favor de interesses divergentes. Por outro lado, na medida em que o Estado estrutura o processo de tomada de decisões, também influencia as formas pelas quais se dá a ação coletiva e a mobilização em defesa dos diversos interesses sociais. Mais do que isso, pode influenciar o próprio conteúdo das demandas políticas e os momentos em que elas emergem (Skocpol, 1999, p. 22-23). Assim, é na interação entre a administração pública e partidos políticos que surgem os temas que compõem a agenda política, bem como as formulações dos partidos e da administração tendem a respeitar os modelos de políticas já instituídos.

$\mathrm{Na}$ análise de Rueschemeyer e Evans (1999) a eficiência do Estado em intervir na sociedade ou no mercado depende das capacidades da estruturação de seu aparato burocrático e de sua autonomia em relação aos interesses sociais. A questão fundamental encontra-se em compreender de que maneira o desenvolvimento de longo prazo de suas instituições, via de regra pensadas para atuar no curto prazo e para questões específicas, limita sua capacidade de intervenção. Especialmente, a intervenção voltada para a redistribuição de recursos é fortemente dependente das características que dado Estado desenvolveu ao longo de sua história, uma vez que atuar em oposição às regras normais do mercado e da sociedade demanda maior capacidade de processar informações e articular agências na implementação das decisões.

No mesmo sentido, Weir e Skocpol (1999, p. 118-119) apontam que em decorrência da forma pela qual estão estruturadas as capacidades coercitivas, fiscais, judiciais e administrativas do Estado, os políticos ou burocratas que ocupam postos na estrutura tendem a utilizar os instrumentos políticos que lhes são disponíveis para responder às demandas sociais, sem maiores inovações. Além disso, a estrutura das capacidades estatais e as políticas já implementadas limitam as concepções pelas quais as questões sociais são compreendidas. Logo, limitam as formas pelas quais as demandas sociais são transmitidas e as respostas aos problemas sociais, formuladas. 
Assim, "as políticas públicas existentes influenciam as demandas políticas dos grupos e partidos que se opõem, o que define suas opções em resposta as práticas correntes”, inclusive porque "os recursos e tempo requeridos para criar novas capacidades desencorajam mudanças radicais de políticas públicas” (ibidem, p. 120-121).

No mesmo sentido, North (2006) destaca que a estabilidade institucional é reforçada pela atuação das organizações. Menos do que jogadores oniscientes, as organizações - como partidos, sindicatos, grupos de interesses, órgãos da burocracia aprendem fazendo, o que significa que as aptidões e rotinas que desenvolvem são conseqüências de suas interações repetidas sob determinados contextos institucionais (ibidem, p. 100). Em conseqüência, "los incentivos que están interconstruidos en el marco institucional desempeñan la función decisiva en la formación de los tipos de aptitudes y conocimiento que son codiciables" (ibidem, p. 105). Dessa forma, as organizações bem adaptadas às instituições existentes tenderão a agir no sentido de preservá-las, mesmo quando essas instituições são ineficientes e aumentam os custos de negociação e transação entre os atores sociais.

Portanto, as políticas sociais - que implicam em intervenção estatal redistributiva e criam fortes relações entre Estado e grupos sociais - estão especialmente sujeitas à dependência de trajetória. Pierson (2004) salienta que processos de feedback positivos podem transformar uma relação de conflito balanceado em uma de grande desigualdade, pois um conflito aberto, no qual um grupo impõe suas preferências a outro, com o tempo pode transformar-se em controle de agenda e manipulação ideológica. Retornos positivos no tempo podem simultaneamente aumentar assimetrias de poder e também tornar as relações de poder menos visíveis (ibidem, p. 37). Ou seja, o exercício de autoridade juntamente com o conjunto de instituições que legitimam seu poder constituem uma fonte de feedback positivo que gera efeitos incrementais no processo de path-dependence.

Para Pierson (2004, p. 811-812), as estruturas do estado de bem-estar social contemporâneo e as políticas públicas ao seu redor refletem fortemente esses efeitos de dependência de trajetória. Destaca-se, desta maneira, dois importantes fatores de estabilização concernentes ao processo de dependência de trajetória no que tange à atuação dos partidos políticos em face das políticas sociais. Por um lado, o partido político pode desenvolver determinada trajetória em sua relação com grupos de interesses externos, com as políticas existentes ou, no limite, com o próprio eleitorado ao qual está associado. Esta trajetória, inscrita nos apelos lançados pelo partido, pode trazer maiores dificuldades para mudanças - sobretudo se o partido obteve sucesso e a estabilidade de seus líderes depender das relações firmadas. 
Por outro lado, para se promover modificações nas políticas sociais é necessário vencer obstáculos relevantes. Isso tendo em vista que as organizações e indivíduos cujos comportamentos já estão adaptados a uma política estabelecida não estarão dispostos a arcar com os custos da readaptação e da incerteza em relação aos futuros resultados das novas iniciativas. Será tão mais difícil alterar determinada política social quanto mais complexas forem as relações que elas envolvem (maior número e diferentes atores sociais e políticos, desde beneficiários até os responsáveis por sua execução, e maior abertura para participação destes atores nos processos de regulamentação das políticas).

\section{VETO-PLAYER E POLÍTICA SOCIAL}

A teoria dos atores com poder de veto, desenvolvida por Tsebelis (2009) observa como diferentes instituições políticas apresentam possibilidades e implicações diferentes no processo de produção de decisões e políticas públicas. Este estudo aponta que mudanças no status quo de determinada política exige a concordância de todos os atores - individuais ou coletivos - que possam impedir (vetar) a implementação de alterações. Os partidos políticos inserem-se nesta teoria como atores coletivos com poder de veto sempre que, em determinado contexto legislativo, por determinação das regras que fixam o processo decisório, sua participação nas coalizões de defesa ou obstrução das propostas de mudanças for capaz de influenciar sua aprovação (Tsebelis, 2009, p. 119).

A parte teórica do trabalho organizado por Haggard e McCubbins (2001) desenvolve uma abordagem sobre o impacto das regras eleitorais sobre os partidos políticos e, em decorrência, sobre o processo de produção de políticas públicas. Os autores também trabalham a idéia de ator de veto: as pessoas (parlamentares/presidente), o partido político ou a facção de partido capaz de, sozinho, exercer o veto em determinada matéria. Quanto mais atores de vetos participam do processo de produção de políticas públicas, maiores são os custos de transação envolvidos e mais o sistema político torna-se resoluto (capacidade de manter acordos sobre políticas no tempo). Ao passo que, quanto menos atores de vetos, torna-se mais fácil para o sistema político negociar e aprovar mudanças na política pública: ou seja, torna-se mais decisivo (capacidade de produzir políticas e mudanças). Um sistema mal equilibrado entre estes dois valores pode ser ingovernável por falta de decisividade (paralisia decisória, pork elevado) ou por falta de resolutividade (falta de checks e balances, falta de confiança sobre os compromissos). 
Já o número de atores de vetos em cada sistema político é calculado a partir da diversidade de interesses criadas no sistema político com a separação de poder (existência de pontos de veto) e da divisão de propósito (diversidade de preferência dos atores que controlam os pontos de veto) (Haggard e McCubbins, 2001, p. 31). Especificamente quanto à divisão de propósito, os autores centram-se na análise dos efeitos do sistema eleitoral sobre as organizações partidárias. O principal argumento é o seguinte: sistemas eleitorais que favorecem multipartidarismo e partidos fracos (divisões internas/personalismo) levam a maior divisão de propósito no sistema político. Os autores também percebem que sistemas com elevada divisão de propósito (partidos fracos) aumentam os custos de negociação para políticas de bens públicos, favorecem acordos de pork-barrel. Por outro lado, se partidos fortes são relevantes para políticas de bens públicos, muita concentração de poder nos líderes dos partidos pode levar a representantes não responsivos aos eleitores.

Como limites da abordagem dos atores com poder de veto, apresenta-se em primeiro planto a questão das políticas substantivas. Como aponta Tsebelis (2009, p. 38 ), o sentido das políticas em jogo quando se analisa os pontos de veto só pode ser compreendido se as preferências dos atores forem identificadas. E estas preferências podem ser mais instáveis e difíceis de atribuir do que a literatura geralmente supõe. Por exemplo, Grossback, Peterson e Stimson (2007) revelam o efeito mandato de determinadas conjunturas provenientes de eleições presidenciais nos Estados Unidos, que altera substancialmente o comportamento dos representantes nas casas legislativas. Existem momentos em que a opinião pública, expressada nas eleições presidenciais, é forte e clara o suficiente para alterar momentaneamente as preferências dos legisladores e outros atores políticos, superando pontos de veto e tornando mais fácil a mudança do status quo.

\section{CONCLUSÃO}

A pesquisa de revisão apresentada no artigo, que contempla a algumas das principais interpretações sobre a relação entre partidos e as políticas sociais, permite observar que as teorias mais novas não fazem tábua rasa das anteriores. Ao contrário, aproveitam as contribuições geradas e exploram os pontos não explicados, gerando ganhos para acumulação do conhecimento. Além disso, as gerações não se esgotam, mas se desenvolvem em contato com as novas teorias e os acontecimentos que lhe são contemporâneos. Por isso, torna-se importante conhecer os subsídios que as diferentes teorias fornecem para análise da origem, manutenção e modificação das políticas sociais. O quadro abaixo oferece uma síntese da pesquisa realizada. 
Quadro 1 - Abordagens teóricas sobre as políticas sociais

\begin{tabular}{|c|c|c|c|}
\hline & & Argumentos & Críticas \\
\hline \multirow{2}{*}{$\begin{array}{l}\text { Primeira } \\
\text { Geração }\end{array}$} & $\begin{array}{l}\text { Lógica do } \\
\text { industrialismo }\end{array}$ & $\begin{array}{l}\text { Funcionalista (versão fraca): industrialismo é } \\
\text { a causa necessária para o surgimento de } \\
\text { políticas de bem-estar, governo responde às } \\
\text { necessidades sociais e tecnológicas. }\end{array}$ & $\begin{array}{l}\text { Não explica a variação } \\
\text { entre os regimes de } \\
\text { bem-estar, nem os } \\
\text { países socialistas. }\end{array}$ \\
\hline & $\begin{array}{l}\text { Lógica do } \\
\text { capitalismo } \\
\text { (neo-marxista) }\end{array}$ & $\begin{array}{l}\text { Funcionalista (versão forte): os níveis de } \\
\text { desenvolvimento econômico são } \\
\text { determinantes dos níveis de bem-estar, } \\
\text { dadas as necessidades de reprodução social } \\
\text { no capitalismo avançado. }\end{array}$ & $\begin{array}{l}\text { Difícil de operacionalizar } \\
\text { para comparação entre } \\
\text { países, sem caso de } \\
\text { controle (país socialista } \\
\text { e democrático). }\end{array}$ \\
\hline \multirow{2}{*}{$\begin{array}{l}\text { Segunda } \\
\text { Geração }\end{array}$} & $\begin{array}{l}\text { Teoria da } \\
\text { Modernização } \\
\text { (society- } \\
\text { centered) }\end{array}$ & $\begin{array}{l}\text { Modelo pluralista: todos os regimes políticos } \\
\text { levam à redistribuição, Estado responde à } \\
\text { demanda popular, níveis de redistribuição } \\
\text { dependem da estrutura do mercado político, } \\
\text { fatores como o sufrágio universal explicam } \\
\text { políticas de bem-estar. }\end{array}$ & $\begin{array}{l}\text { Explicação causal pouco } \\
\text { sofisticada e generalista, } \\
\text { não explica variação } \\
\text { complexa, agregação de } \\
\text { variáveis e perspectiva } \\
\text { universalista. }\end{array}$ \\
\hline & $\begin{array}{l}\text { Modelo social- } \\
\text { democrata } \\
\text { (society- } \\
\text { centered) }\end{array}$ & $\begin{array}{l}\text { Partidos políticos importam: trabalhadores } \\
\text { podem utilizar o Estado democrático para } \\
\text { redistribuição social no capitalismo, partidos } \\
\text { são instrumentos de interesses. O nível do } \\
\text { bem-estar depende da força e das relações } \\
\text { entre partidos de esquerda/direita e dos } \\
\text { sindicatos - mobilização é condição. }\end{array}$ & $\begin{array}{l}\text { Não captura os } \\
\text { mecanismos de } \\
\text { transmissão da disputa } \\
\text { política para as políticas } \\
\text { públicas. }\end{array}$ \\
\hline \multirow{2}{*}{$\begin{array}{l}\text { Terceira } \\
\text { Geração }\end{array}$} & $\begin{array}{l}\text { Novo } \\
\text { instituciona- } \\
\text { lismo histórico } \\
\text { (state-centered) }\end{array}$ & $\begin{array}{l}\text { Abordagem institucional e path-dependece: } \\
\text { Estado é ator autônomo, pode ser insulado. } \\
\text { Organização e estrutura do Estado } \\
\text { modificam relações entre classes/partidos, } \\
\text { podem institucionalizar representação e } \\
\text { canais de negociação (gerando dependência } \\
\text { da trajetória com feedback positivo). }\end{array}$ & $\begin{array}{l}\text { Coloca em segundo } \\
\text { plano a capacidade de } \\
\text { mudança de trajetória e } \\
\text { diferenciação das } \\
\text { políticas no curto prazo. }\end{array}$ \\
\hline & $\begin{array}{l}\text { Modelo do veto- } \\
\text { player } \\
\text { (state-centered) }\end{array}$ & $\begin{array}{l}\text { Abordagem institucional (pontos de vetos): } \\
\text { Aponta como as regras formais da } \\
\text { competição política limitam e estruturam as } \\
\text { possibilidades de atores/partidos na } \\
\text { produção de políticas públicas. Amplia } \\
\text { comparabilidade entre sistemas. }\end{array}$ & $\begin{array}{l}\text { Formalização da análise } \\
\text { tende a abstrair } \\
\text { elementos concretos da } \\
\text { relação de poder entre } \\
\text { atores. }\end{array}$ \\
\hline
\end{tabular}

As teorias apresentadas oferecem diferentes parâmetros para compatibilização teórica entre os processos de agregação de interesses e de ação governamental e, ainda, na definição de canais e interveniências do processo de accountability vertical. À guisa de conclusão, busca-se evidenciar os elementos presentes nas interpretações das 
políticas sociais segundo estes critérios. As interpretações de primeira geração (lógica do industrialismo e do capitalismo) conferem um papel condicionado para os atores políticos, subsidiário das etapas ou momentos do desenvolvimento industrial ou do sistema capitalista. Neste sentido, seus argumentos teóricos supõem que o processo de agregação de interesses é condicionado por estes elementos estruturais, implicando em políticas públicas coerentes e equivalentes ao processo econômico.

Diferente da lógica do industrialismo, abordagens posteriores que ocorrem na tradição do pensamento marxista passaram a valorizar aspectos "superestruturais", como a atuação dos partidos e outros setores de agregação de interesses. Embora as possibilidades de disrupção das constrições do processo produtivo sejam desconsideradas na lógica do capitalismo, um papel parcialmente autônomo dos atores sociais é levado em consideração como intermediador das exigências estruturais e as políticas sociais. Ainda ligada à visão etapista e funcionalista presente na primeira geração, a teoria da modernização compreende que sociedades com determinados níveis de complexidade tornam-se aptas a realizar o processo de integração de interesses via partidos políticos. Entretanto, a efetiva realização desta atividade pelos partidos exige que as organizações sociais previamente existentes - tradicionais sejam suplantadas pelas dinâmicas dos partidos, bem como sejam superadas as instabilidades decorrentes dos momentos de transição.

A teoria da modernidade é a primeira a apontar que os partidos podem realizar a conexão entre cidadania e políticas públicas, no sentido de assegurar preferências políticas na ação governamental com um papel autônomo em relação aos elementos estruturais. Explorando esta possibilidade, as pesquisas focadas na atuação dos partidos políticos inferem a conexão entre cidadania, partidos e políticas públicas como algo bastante claro, embora não isento de intervenções econômicas e do próprio ambiente político. A presença ou ausência de determinados atores políticos, as oportunidades de coalizões e o sucesso eleitoral das diferentes forças possuem, nesta abordagem, capacidade de criar e modificar - ainda que com efeitos incrementais - a estrutura e o gasto nas políticas sociais.

São abordagens que podem ser consideradas do tipo society-centered, pois apresentam fatores do campo da economia e da sociedade como determinantes para a ação governamental. A terceira geração de teorias estudada, ao contrário, busca em fatores estruturais ou institucionais as explicações para consolidação de determinados padrões de políticas públicas. Podem ser consideradas, assim, de tipo state-centered. A primeira delas, o novo institucionalismo histórico, defende que as diferentes formas pelas quais o Estado se estrutura ao longo do tempo condicionam e influenciam as 
capacidades de provimento de políticas públicas e as condições de grupos e atores sociais em modificá-las.

Para estas interpretações, o processo de conexão entre cidadania e política pública sofre a interferência da capacidade estatal em promover intervenção na sociedade ou na economia, bem como das relações entre os diferentes campos estatais e sua autonomia em relação à própria sociedade. Além disso, as preferências sociais seriam influenciadas pelas formas historicamente desenvolvidas de resolução dos problemas. Por fim, ainda no campo da geração institucional, os modelos de atores com poder de veto abstraem o conteúdo histórico destas análises, sintetizando as regras formais que alteram as relações entre os atores, determinando as possibilidades de mudança da política pública.

Destaca-se que ao lado destas teorias, as contribuições sobre a formação e mudanças nas políticas de bem-estar com metodologias que combinam diversos elementos. Conforme Myles e Quadagno (2002, p. 39) foi Esping-Andersen, em seu The Three Worlds of Welfare Capitalism, quem demonstrou de maneira mais persuasiva a importância tanto da política quanto das instituições na formação das políticas de bem-estar. Neste sentido, Esping-Andersen desenvolveu uma análise histórico-comparativa com grande capacidade de explicar a variação existente e as transformações das políticas de bem-estar (Ferrera, 2002, p. 169).

Quanto às causas dos diferentes regimes de bem-estar, as hipóteses apresentadas por Esping-Andersen (1998, p. 53-54; 103) envolvem a interação entre relações históricas de longa duração (conservadorismo/liberalismo), as relações entre atores políticos e a cristalização de padrões nos sistemas de políticas públicas pela atuação do Estado. Fora dos sistemas ocidentais, destaca-se a análise de Haggard e Kaufman (2008) sobre América Latina, Leste Asiático e Europa Oriental. Os autores também desenvolvem uma análise histórico-comparativa, que apontam como conjuntural, explorando as trajetórias dos diversos países e as relações entre arranjos político-institucionais, estrutura econômica e atores sociais, políticos e econômicos. 


\section{REFERÊNCIAS BIBLIOGRÁFICAS}

ALMOND, Gabriel A. COLEMAN, James S. (org). A Política das Áreas em

Desenvolvimento. Rio de Janeiro: Freitas Bastos, 1969.

ALMOND, Gabriel A. POWEL, Bingham. Uma Teoria de Política Comparada. Rio de Janeiro: Zahar, 1972.

CASTLES, Francis G. Developing new measures of welfare state change and reform. European Journal of Political Research, n. 41, 2002, p. 613-641.

CASTLES, Francis C (org). The Impact of Parties: politics and policies. London: Sage, 1982.

ESPING-ANDERSEN, Gøsta. The Three Worlds of Welfare Capitalism. Princeton: Princeton University, 1998.

FERRERA, Maurizio. La Comparación y el Estado del Bienestar: ¿̇un caso de éxito?. In SARTORI, Giovanni. MORLINO, Leonardo (org). La comparación en las ciencias sociales. Madrid: Alianza, 2002. p. 151-177.

GROSSBACK. Lawrence J. PETERSON, David A. M. STIMSON, James A. Mandate Politics. Cambridge: Cambridige University, 2007.

HAGGARD, Stephan. KAUFMAN, Robert R. Development, Democracy, and Welfare States: Latin America, East Ásia, and Eastern Europe. Princeton: Princeton University, 2008.

HAgGaRD, Stephan. McCUBBInS, Mathew. Presidents, Parliaments, and Policy. Cambridge: Cambridige University, 2001.

HUNTINGTON, Samuel P. A Ordem Social nas Sociedades em Mudança. Rio de Janeiro: Forense-Universitária, 1975.

KERR, Clark. DUNLOP, John T. HARBISON, Frederick H. MYERS, Charles A. Industrialismo e Sociedade Industrial. Rio de Janeiro: Fundo de Cultura, 1963. KING, Athony. Political Parties in Western Democracies: Some Sceptical Reflecrions. Polity, n. 2, p. 111-141, 1969.

KLINGEMANN, Hans-Dieter. HOFFERBERT, Richard I. BUDGE, Ian. Parties, Policies, and Democracy. Boulder, San Francisco, Oxford: Westview, 1994.

LENHARDT, Gero. OFFE, Claus. Teoria do Estado e Política Social: Tentativas de Explicação Político-Sociológica para as Funções e os Processos Inovadores da Política Social. In OFFE, Claus. Problemas Estruturais do Estado Capitalista. Rio de Janeiro: Tempo Brasileiro, 1984. p. 10-55.

MARSHALL, Gordon (org). Oxford Dictionary of Sociology. New York: Oxford, 1998.

MARSHALL, T. H. Política Social. Rio de Janeiro: Zahar, 1967.

MARX, Karl. A Origem do Capital: a acumulação primitiva. 4. ed. São Paulo: Global, 1981. 
MARX, Karl. O Capital: crítica da economia política. Vol. 1. 2. ed. São Paulo: Nova Cultural, 1985.

MYLES, John. QUADAGNO, Jill. Political Theories of the Welfare State. Social Service Review, p. 34-57, mar. 2002.

NORTH, Douglass C. Instituciones, Cambio Institucional y Desempeño

Económico. México D.F.: Fondo de Cultura Económica, 2006.

OFFE, Claus. Capitalismo Desorganizado: transformações contemporâneas do trabalho e da política. São Paulo: Brasiliense, 1986.

OFFE, Claus. Partidos Políticos y Nuevos Movimentos Sociales. Madrid: Sistema, 1993.

PIERSON, Paul. Polities in Time: history, institutions, and social analysis. Princeton: Princeton University, 2004.

RUESCHEMEYER, Dietrich. EVANS, Peter B. The State and Economic Transformation: Toward an Analysis of the Conditions Underlying Effective Intervention. In. EVANS, Peter B. RUESCHEMEYER, Dietrich. SKOCPOL, Theda (org). Bring the State Back In. Cambridge: Cambridge University, 1999. p. 44-77. SCHONFELD, William R. Political Parties: The Functional Approach and the Structural Alternative. Comparative Politics, n. 15, p. 477-499, 1983.

SKOCPOL, Theda. AMENTA, Edwin. States and Social Policies. Annual Review of Sociology, 1986, p. 131-157.

SKOCPOL, Theda. Bring the State Back In: Strategies of Analysis in Current Research. In. EVANS, Peter B. RUESCHEMEYER, Dietrich. SKOCPOL, Theda (org). Bring the State Back In. Cambridge: Cambridge University, 1999. p. 3-37.

TILLY, Charles. Grandes estructuras, procesos amplios, comparaciones enormes. Madrid: Alianza, 1991.

TSEBELIS, George. Atores com Poder de Veto: como funcionam as instituições políticas. Rio de Janeiro: FGV, 2009.

WEIR, Margaret. SKOCPOL, Theda. State Structures and the Possibilities for "Keynesian" Responses to the Great Depression in Sweden Britain, and the United States. In. EVANS, Peter B. RUESCHEMEYER, Dietrich. SKOCPOL, Theda (org).

Bring the State Back In. Cambridge: Cambridge University, 1999. p. 107-163. 